\title{
Acyclic artificial nucleic acids with phosphodiester bonds exhibit unique functions
}

\author{
Hiromu Kashida ${ }^{1,2}$, Keiji Murayama ${ }^{1}$ and Hiroyuki Asanuma ${ }^{1}$
}

Artificial nucleic acids (XNAs) have potential as therapeutic agents and fluorescent probes. These acyclic nucleic acid mimics have several advantages, including facile chemical synthesis and resistance to nuclease-mediated cleavage. Here we review our recent progress on the preparation of acyclic XNAs. Acyclic D-threoninol nucleic acid (D-aTNA) forms an extremely stable homo-duplex with complementary D-aTNA, but D-aTNA does not form a stable duplex with either DNA or RNA. Serinol nucleic acid (SNA), which has nucleobases on a serinol backbone, forms stable hybrid helices with both DNA and RNA and has unique chiroptical properties. Both chirality and helicity of an SNA duplex depend on its sequence. L-aTNA, which is an enantiomer of D-aTNA, has the highest affinity for complementary DNA and RNA among these three XNAs. Attempts to apply these XNAs as drugs, fluorescent probes, and nanomaterials are underway. Although chemical differences among these XNAs are small, all have unique properties, and XNAs with different functional characteristics will be found by chemically modifying these XNAs.

Polymer Journal (2016) 48, 781-786; doi:10.1038/pj.2016.39; published online 20 April 2016

\section{INTRODUCTION}

The development of artificial nucleic acids, or xeno nucleic acids (XNAs), that form stable duplexes with natural nucleic acids has been challenging. A vast number of XNAs have been reported, and some have found utility in biotechnology, medicine and nanotechnology. ${ }^{1-3}$ Among these, a major strategy for the synthesis of oligomers that form stable duplexes with natural nucleic acids has been to use neutral backbones. Peptide nucleic acids (PNAs) are one of the most widely used XNAs in the first category (Figure 1). ${ }^{4}$ PNAs have a neutral peptide backbone instead of a phosphodiester backbone and thus have no charge. PNAs can form stable duplexes with complementary DNA and RNA without requiring cation condensation. Chiral PNAs have been reported that differentially recognize natural nucleic acids depending on their chirality. ${ }^{5-7}$ Morpholino nucleic acids, which also have no charge, are also representative of the class of nucleic acids with neutral backbones (Figure 1). ${ }^{8}$

$\mathrm{XNAs}$ of another type have a constrained backbone. Locked nucleic acids (LNAs) belong to this category (Figure 1). ${ }^{9,10}$ LNAs contain a methylene linkage between the $2^{\prime}$-oxygen and the $4^{\prime}$-carbon of D-ribose, locking the sugar puckers into the $3^{\prime}$-endo conformation adopted by RNA. Consequently, LNA has high affinity for RNA due to a lower decrease in entropy upon duplex formation. Other XNAs with bicyclic or tricyclic backbones, such as tricyclo-DNA, have also been reported (Figure 1). ${ }^{11,12}$

Another strategy involves incorporation of acyclic base surrogates onto a DNA backbone. ${ }^{13-17}$ Benner's group first reported flexible nucleic acids, which have nucleobases on flexible propanediol linkers. ${ }^{18-20}$ Unlocked nucleic acids, in which there is no bond between $2^{\prime}$ and $3^{\prime}$ carbons of the ribose sugar, were reported by Wengel's group. ${ }^{21,22}$ However, incorporation of these modified nucleotides into DNA or RNA often severely lowered the stability of the duplexes. Meggers et al. reported glycerol nucleic acids (GNAs), which tether nucleobases through an acyclic C2 linker (Figure 1). ${ }^{23-26}$ Quite surprisingly, a GNA oligomer, which is composed of only GNA monomers, formed a highly stable duplex with a complementary GNA oligomer even though GNA has a relatively flexible structure and phosphodiester bonds. The melting temperature of the GNA homo-duplex was much higher than those of DNA and RNA homo-duplexes of the same sequence. This high stability of the GNA homo-duplex showed that a cyclic sugar is not necessary for stable duplex formation. GNAs showed strong sequence dependence in the context of hetero-duplexes; they do not form stable duplexes with either DNA or RNA when the GC content is high. ${ }^{26}$

Inspired by these pioneering studies, several groups, including ours, have synthesized and characterized fully modified acyclic XNAs with phosphodiester linkages. ${ }^{27-29}$ There are several advantages of acyclic scaffolds over other XNAs. First, the synthetic costs of acyclic XNA are often low due to their simple structures. Second, chemical modification is usually facile, allowing XNAs with novel structures to be easily prepared. Third, because their chemical structures are very different from natural nucleic acids, they are highly resistant to nucleases. In addition, acyclic XNAs with phosphodiester bonds are usually highly water-soluble, in contrast to neutral XNAs. Furthermore, acyclic XNAs are candidates for genetic material in the 'pre-RNA world' because of their simple structures. ${ }^{30,31}$ Here we review our recent work on acyclic XNAs. Our group has developed three

\footnotetext{
${ }^{1}$ Department of Molecular Design and Engineering, Graduate School of Engineering, Nagoya University, Nagoya, Japan and ${ }^{2}$ PRESTO, Japan Science and Technology Agency, Kawaguchi, Saitama, Japan

Correspondence: Dr H Kashida, Department of Molecular Design and Engineering, Graduate School of Engineering, Nagoya University, Furo-cho, Chikusa-ku, Nagoya 464-8603, Japan.

E-mail: kashida@nubio.nagoya-u.ac.jp

Received 25 December 2015; revised 11 February 2016; accepted 16 February 2016; published online 20 April 2016
} 
acyclic XNAs: acyclic D-threoninol nucleic acid (D- $a$ TNA), serinol nucleic acid (SNA) and acyclic L-threoninol nucleic acid (L-aTNA). Though structural differences are marginal, each of these XNAs has unique properties.

\section{D-aTNA IS HIGHLY ORTHOGONAL TO NATURAL NUCLEIC ACIDS}

In our previous studies, various types of molecules, including fluorophores and photoresponsive moieties, were incorporated into DNA via D-threoninol. ${ }^{32,33}$ Although the chemical structures of these base surrogates are very different from those of natural nucleobases, duplexes between natural nucleic acids and D-threoninol are stabilized through stacking interactions. Therefore, we selected D-threoninol as a linker for tethering natural nucleobases and developed D- $a$ TNA. ${ }^{34}$ We synthesized D- $a$ TNA phosphoramidite monomers, and D- $a$ TNA oligomers were synthesized using a DNA/RNA synthesizer (Figure 2). D-aTNA formed extremely stable duplexes with complementary D- $a \mathrm{TNA}$; the melting temperature $\left(T_{\mathrm{m}}\right)$ of homoduplexes of an 8 -mer of D- $a$ TNA was as high as $62.7^{\circ} \mathrm{C}$, much higher than the $T_{\mathrm{m}}$ of either DNA or RNA homo-duplexes of the same sequence $\left(29.0^{\circ} \mathrm{C}\right.$ or $38.9^{\circ} \mathrm{C}$, respectively). The $T_{\mathrm{m}}$ of homo-duplexes of other acyclic XNAs, including PNA, GNA and SNA, is also lower. ${ }^{35}$ Thermodynamic analyses indicated that the D- $a$ TNA homo-duplexes are more stable than those of natural nucleic acids due to enthalpic contributions. The molecular mechanism may involve strong stacking interactions between bases, allowed by the flexible backbone and/or the hydrogen bonds between the amide group and the phosphate backbone.

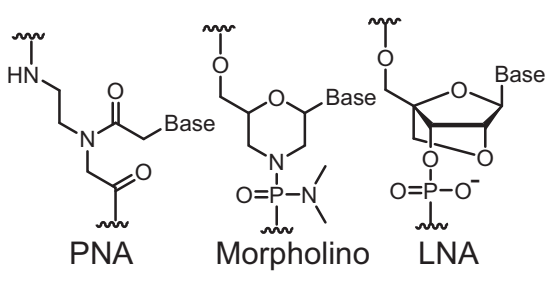

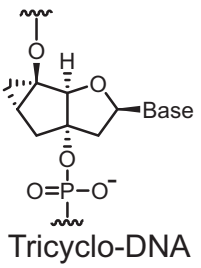<smiles>COC[C@H](CBr)OP(=O)([O-])[Si]#N</smiles><smiles>CCOC[C@H](NC(=O)C[18O])C(C)P(=O)([O-])[O-]</smiles><smiles>COC[C@H](COP(=O)([O-])[N+]([NH3+])([NH3+])[O-])NC(=O)CBr</smiles><smiles>C1CCCC1</smiles>

Figure 1 Chemical structures of representative XNAs.

In spite of the high stability of D- $a$ TNA homo-duplexes, D- $a$ TNA did not form stable duplexes with natural DNA or RNA. The $T_{\mathrm{m}} \mathrm{s}$ of D- $a \mathrm{TNA} / \mathrm{DNA}$ and D-aTNA/RNA 8-mer duplexes were too low to measure (Table 1). D-aTNA exhibits high orthogonality to natural nucleic acids. There may be applications in which this is an asset: for example, D- $a$ TNA could hybridize with complementary D- $a$ TNA without interference from natural nucleic acids in cells.

\section{DEVELOPMENT OF SNA WITH UNIQUE CHIROPTICAL PROPERTIES}

D- $a$ TNA cannot hybridize with DNA or RNA in spite of the extremely high stability of its homo-duplex. We hypothesized that D-aTNA is not flexible enough to conform to the more rigid DNA or RNA. We then synthesized a more flexible XNA, SNA, which has natural

Table 1 Melting temperatures of XNAs and natural nucleic acids

\begin{tabular}{|c|c|c|c|}
\hline Duplex & Sequence & Direction & $\mathrm{T}_{m}\left({ }^{\circ} \mathrm{C}\right)^{a}$ \\
\hline D-aTNA/D-aTNA & $\begin{array}{l}\text { 1'-GCATCAGT-3' } \\
\text { 3'-CGTAGTCA-1' }\end{array}$ & Antiparallel & 62.7 \\
\hline SNA/SNA & $\begin{array}{l}(S) \text {-GCATCAGT- }(R) \\
(R) \text {-CGTAGTCA- }(S)\end{array}$ & Antiparallel & 51.1 \\
\hline L-aTNA/L-aTNA & $\begin{array}{l}\text { 1'-GCATCAGT-3' } \\
\text { 3'-CGTAGTCA-1' }\end{array}$ & Antiparallel & 61.8 \\
\hline DNA/DNA & $\begin{array}{l}\text { 5'-GCATCAGT-3' } \\
\text { 3'-CGTAGTCA-5' }\end{array}$ & Antiparallel & 29.0 \\
\hline RNA/RNA & $\begin{array}{l}\text { 5'-GCAUCAGU-3' } \\
\text { 3'-CGUAGUCA-5' }\end{array}$ & Antiparallel & 38.9 \\
\hline D-aTNA/DNA & $\begin{array}{l}\text { 1'-GCATCAGT-3' } \\
\text { 3'-CGTAGTCA-5' }\end{array}$ & Antiparallel ${ }^{b}$ & n.d. \\
\hline D-aTNA/RNA & $\begin{array}{l}\text { 1'-GCATCAGT-3' } \\
\text { 3'-CGUAGUCA-5' }\end{array}$ & Antiparallel ${ }^{\mathrm{b}}$ & n.d. \\
\hline SNA/DNA & $\begin{array}{l}\text { (S)-GCATCAGT- }(R) \\
\text { 3'-CGTAGTCA-5' }\end{array}$ & Antiparallel ${ }^{b}$ & 23.5 \\
\hline SNA/RNA & $\begin{array}{l}\text { (S)-GCATCAGT-(R) } \\
\text { 3'-CGUAGUCA-5' }\end{array}$ & Antiparallel $^{\mathrm{b}}$ & 35.0 \\
\hline L-aTNA/DNA & $\begin{array}{l}\text { 3'-GCATCAGT-1' } \\
\text { 3'-CGTAGTCA-5' }\end{array}$ & Parallel $^{\mathrm{b}}$ & 28.4 \\
\hline L-aTNA/RNA & $\begin{array}{l}\text { 3'-GCATCAGT-1' } \\
\text { 3'-CGUAGUCA-5' }\end{array}$ & Parallel ${ }^{\mathrm{b}}$ & 41.0 \\
\hline DNA/RNA & $\begin{array}{l}\text { 5'-GCATCAGT-3' } \\
\text { 3'-CGUAGUCA-5' }\end{array}$ & Antiparallel ${ }^{b}$ & 25.7 \\
\hline
\end{tabular}

aConditions: $2.0 \mu \mathrm{m}$ oligonucleotide strand, $100 \mathrm{~mm} \mathrm{NaCl}, 10 \mathrm{~mm}$ phosphate buffer (pH 7.0). n.d. indicates that $T_{m}$ was too low to measure.

birections of hetero-duplexes are defined according to the direction of solid-phase synthesis.

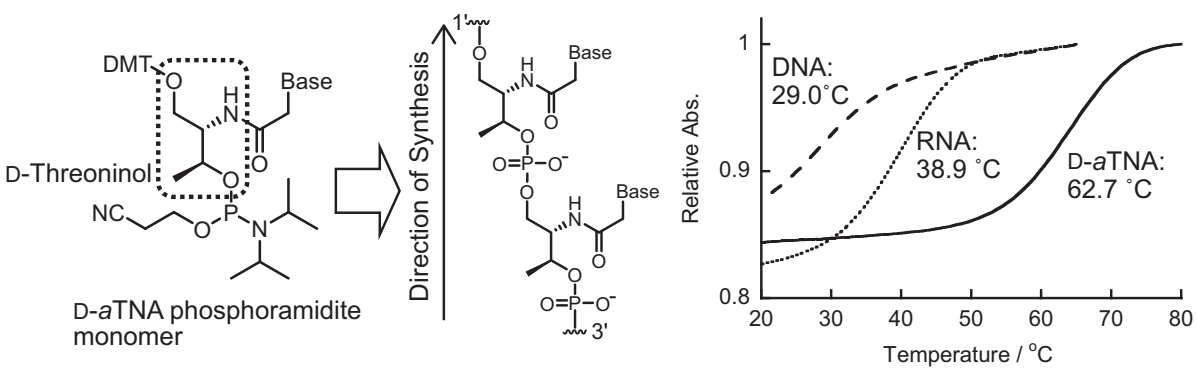

Figure 2 Chemical structure of D-aTNA and melting curves of homo-duplexes of D-aTNA, DNA and RNA of the same sequence: 5'-GCATCAGT-3'/3'CGTAGTCA-5'. Note that D-aTNA has a $1^{\prime}$ terminus rather than a $5^{\prime}$ terminus. In the RNA sequence, $T$ was replaced with $U$. Bases of phosphoramidite monomers are protected by acyl groups. 
bases linked through symmetric serinols (Figure 1). ${ }^{36}$ The difference between the D- $a$ TNA and SNA monomer is a single methyl group; however, SNA exhibited several unique properties. Though serinol itself is achiral, we synthesized enantiopure oligomers from chiral phosphoramidite monomers. The enantiopure SNA oligomer exhibits interesting chiroptical properties, as shown in Figure 3a. The SNA dimer $\mathrm{T} \rightarrow \mathrm{A}$ is the enantiomer of the $\mathrm{A} \rightarrow \mathrm{T}$ sequence. Thus, the chirality of the SNA oligomer can be inverted by reversing the sequence. In contrast, $\mathrm{T} \rightarrow \mathrm{T}$ is the enantiomer of itself. Therefore, an SNA oligomer with a symmetric sequence is achiral (the meso form).

The CD spectrum of an 8-mer SNA homo-duplex $\mathrm{Sa} / \mathrm{Sb}$ is shown in Figure 3b. Positive and negative cotton effects are observed. In contrast, for the duplex of the reversed sequences of $\mathrm{Sa}$ and $\mathrm{Sb}$ $(\mathrm{Sd} / \mathrm{Sc})$, the complete inverse of the $\mathrm{CD}$ signals are observed. Thus, the helicity of SNA homo-duplexes can be inverted by reversing their sequences. On the other hand, the Se/Sf duplex, which has a symmetrical sequence, gives no CD signal, revealing that this duplex is achiral. This unique property is due to the symmetric structure of SNA and cannot be seen in other asymmetric XNAs.

The $T_{\mathrm{m}}$ of an 8 -mer SNA homo-duplex is $51.1^{\circ} \mathrm{C}$ (Table 1 ), much higher than that of natural nucleic acid duplexes of the same sequence. However, the SNA homo-duplex is less stable than the D- $a$ TNA duplex because of the larger entropic loss upon hybridization that is caused by SNA's flexibility. Interestingly, although SNA has a structure similar to that of D- $a$ TNA, SNA forms stable hybrid duplexes with both DNA and RNA. The $T_{\mathrm{m}} \mathrm{s}$ of 8 -mer SNA/DNA and SNA/RNA hetero-duplexes are $23.5^{\circ} \mathrm{C}$ and $35.0^{\circ} \mathrm{C}$, respectively. The $T_{\mathrm{m}}$ of a SNA/RNA duplex is even higher than that of a DNA/RNA duplex, clearly demonstrating that SNAs have the potential to be more efficient than DNAs as probes and drugs that target RNA. To the best of our knowledge, SNA is the first acyclic XNA with phosphodiester bonds that can form stable hetero-duplexes with both DNA and RNA. Our analyses of SNA indicate that a rigid structure or a neutral charge is not required for hetero-duplex formation with natural nucleic acids.

\section{L-aTNA HAS HIGH AFFINITY FOR NATURAL NUCLEIC ACIDS}

The striking differences between D- $a$ TNA and SNA prompted us to synthesize another acyclic XNA, L- $a$ TNA (Figure 1), in which nucleobases are tethered via L-threoninol. ${ }^{37}$ As expected, because $\mathrm{L}-a \mathrm{TNA}$ is an enantiomer of $\mathrm{D}-a \mathrm{TNA}$, the $T_{\mathrm{m}}$ of the 8 -mer $\mathrm{L}-a \mathrm{TNA}$ homo-duplex is almost the same as that of the D- $a$ TNA homo-duplex (Table 1). In sharp contrast, significant differences are observed in the stabilities of their hetero-duplexes with DNA and RNA. Unlike D- $a$ TNA oligomers, L- $a$ TNA oligomers can recognize complementary DNA and RNA. Interestingly, $\mathrm{L}-a \mathrm{TNA}$ prefers to form hetero-duplexes not in an antiparallel but in a parallel manner. The $T_{\mathrm{m}}$ of the 8 -mer L- $a$ TNA/RNA duplex with a sequence designed to enforce hybridization in the parallel direction is $41.0^{\circ} \mathrm{C}$, whereas the melting profile of the L- $a$ TNA/RNA duplex designed to hybridize in the antiparallel direction did not show a sigmoidal curve (Figure 4 and Table 1). The $T_{\mathrm{m}}$ of the parallel hetero-duplex is even higher than those of the corresponding SNA/RNA and RNA/RNA duplexes. Thus, L- $a$ TNA forms a more stable complex with complementary RNA than SNA does. Similarly, the stability of the L-aTNA/DNA duplex is higher than that of the SNA/DNA duplex.

L- $a$ TNA hybridizes with DNA and RNA only in the parallel direction. This is the complete opposite of the preference of SNA, which forms hetero-duplexes only in the antiparallel direction. We attribute this difference to the configuration of the $2^{\prime}$ carbon of these

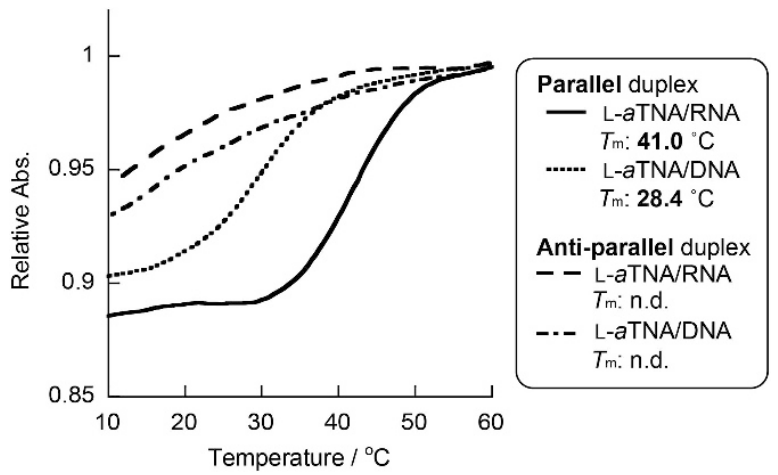

Figure 4 Melting curves of L-aTNA/RNA and L-aTNA/DNA duplexes. The sequences are as follows: 3'-GCATCAGT-1'/3'-CGTAGTCA-5' (parallel direction) and $1^{\prime}$-GCATCAGT-3'/3'-CGTAGTCA-5' (antiparallel direction). In RNA, $U$ was substituted for $T$.
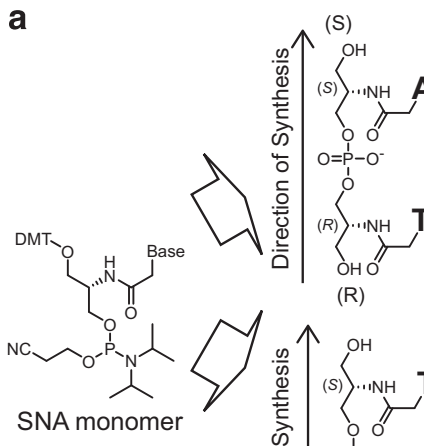

(R)
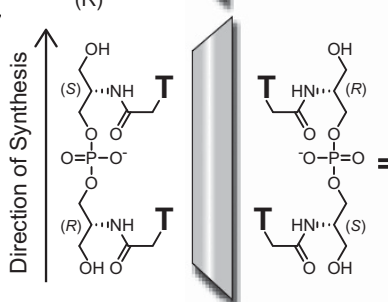
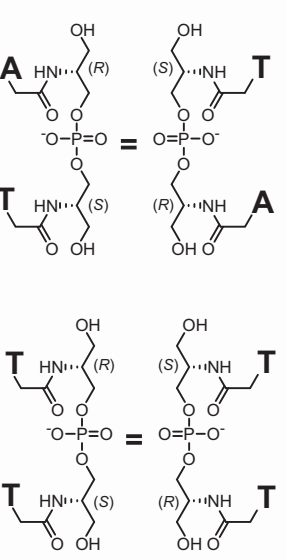

b

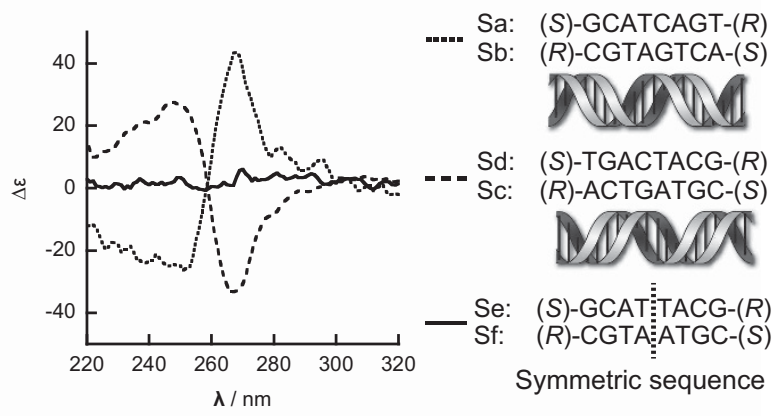

Figure 3 (a) The chemical structure of the SNA phosphoramidite monomer synthesized from L-serine and schematic illustration of chirality inversion of SNA oligomers. (b) Helicities of SNA homo-duplexes can be controlled by sequence design. $(S)$ and $(R)$ termini are named based on the chirality of terminal residues. Bases of phosphoramidite monomers are protected by acyl groups. 

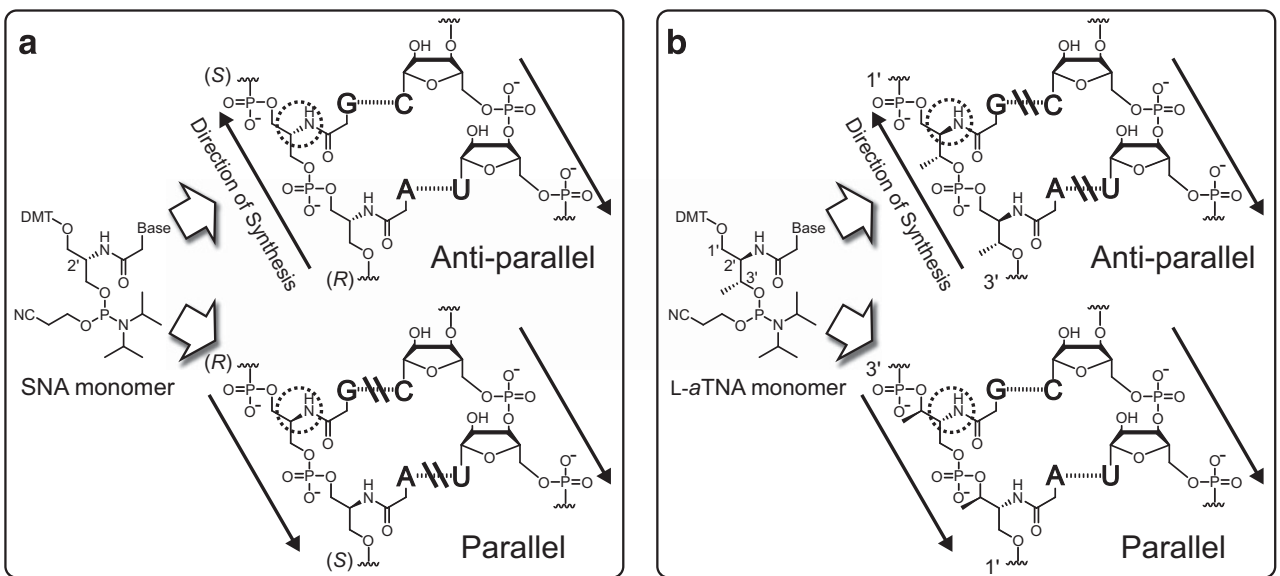

Figure 5 Relationship between sequence direction and configuration of the central carbon of (a) SNA and (b) L-aTNA. SNA forms a duplex with complementary RNA in an antiparallel manner, whereas L-aTNA hybridizes with RNA only in the parallel direction. Directions of amide groups are emphasized with circles. Bases of phosphoramidite monomers are protected by acyl groups.

XNAs (Figure 5). As mentioned above, the chirality of the SNA oligomer can be inverted by reversing its sequence. This means that the configuration at the central carbon of SNA can be inverted by reversing its sequence. The strong preference of SNA for the antiparallel direction indicates that the configuration of the $2^{\prime}$ carbon is essential for DNA/RNA recognition. In contrast, because $2^{\prime}$ carbon of the L-aTNA phosphoramidite monomer has the opposite configuration of that of the SNA monomer, the direction of the amide group in the parallel $\mathrm{L}-a \mathrm{TNA} / \mathrm{RNA}$ duplex corresponds to that in the antiparallel SNA/RNA duplex. Accordingly, L-aTNA can form hetero-duplexes only in the parallel orientation. On the other hand, although the antiparallel D- $a$ TNA/RNA duplex has the same configuration, D- $a$ TNA does not form stable duplexes with DNA or RNA. This result clearly demonstrates that the hybridization properties of these XNAs are highly dependent on the position of the methyl group and on the configuration of $2^{\prime}$ carbon.

The drastic difference between D- $a$ TNA and L- $a$ TNA is also likely due to their helical preferences. The CD spectrum of the D- $a$ TNA homo-duplex is shown in Figure 6. This CD signal resembles that of chiral PNA forming a left-handed helix, ${ }^{6,38,39}$ indicating that D- $a$ TNA prefers to adopt a left-handed helical structure. In contrast, L- $a$ TNA shows the opposite CD signal, which is similar to that of chiral PNA forming a right-handed helix. These results strongly suggest that L-aTNA forms a stable duplex with DNA and RNA due to its preference for a right-handed helical structure formation. The helical preference of $\mathrm{L}-a \mathrm{TNA}$ underlies the higher affinity of $\mathrm{L}-a \mathrm{TNA}$ for RNA compared with SNA.

\section{SUMMARY AND OUTLOOK}

In summary, we have developed three acyclic XNAs with unique properties (Figure 7). These XNAs have simple structures, making their synthesis straightforward and each can form an extremely stable homo-duplex. Their abilities to recognize natural nucleic acids vary and are highly dependent on chemical structure. D- $a$ TNA and L- $a$ TNA form the most stable homo-duplexes among these acyclic XNAs. In an example of an important contrast, D- $a$ TNA does not form a stable hetero-duplex with DNA or RNA, whereas L- $a$ TNA does. This high orthogonality to natural nucleic acids could make it possible to use D- $a$ TNA as a nanomaterial that functions inside a cell without interfering with cellular nucleic acids. Our group has

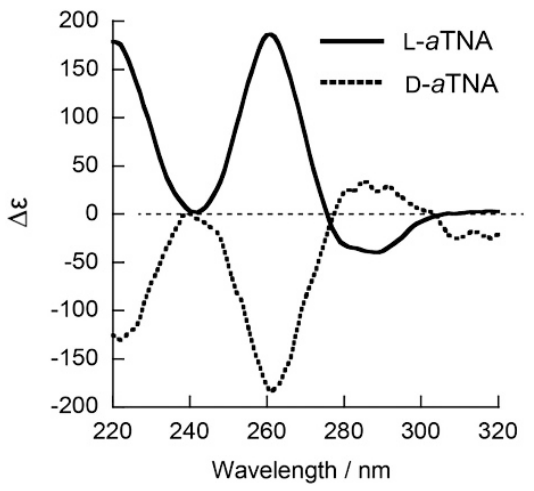

Figure 6 CD spectra of 8-mer L-aTNA and D-aTNA duplexes. Sequences are as follows; $1^{\prime}$-TGACTACG-3'/3'-ACTGATGC-1'.

begun to investigate the operation of nanomachines composed of D- $a$ TNA.

SNA, which lacks a methyl group that is present in D- $a$ TNA, has a unique chiroptical property: the chirality and helicity of SNA oligomers can be controlled in the design of the sequence. This property stems from the symmetric structure of SNA and makes it unique because most XNAs are asymmetric. In addition, in contrast to D- $a$ TNA, SNA forms stable hybrid duplexes with both DNA and RNA. The SNA/RNA duplex was more stable than the DNA/RNA duplex, and SNA is resistant to nuclease degradation, clearly demonstrating the potential of SNA as a diagnostic probe and therapeutic. We have developed molecular beacons composed of SNA and demonstrated that these probes can be used to visualize mRNA in cells. ${ }^{40}$ We have also incorporated SNA monomers at the termini of siRNAs; these conjugates activate RNAi-mediated gene silencing and have excellent enzymatic durability. ${ }^{41}$

As we reported recently, L- $a$ TNA has the highest affinity to natural nucleic acids among the three acyclic XNAs. The L-aTNA/RNA duplex is even more stable than the SNA/RNA duplex. Thus, L- $a$ TNAs have potential for use as probes and drugs that target natural nucleic acids. Because the three acyclic XNAs presented here have unique properties, each should have applications as tools in biology, biotechnology and nanotechnology. The large difference among the properties of these XNAs was a surprise because their structural 


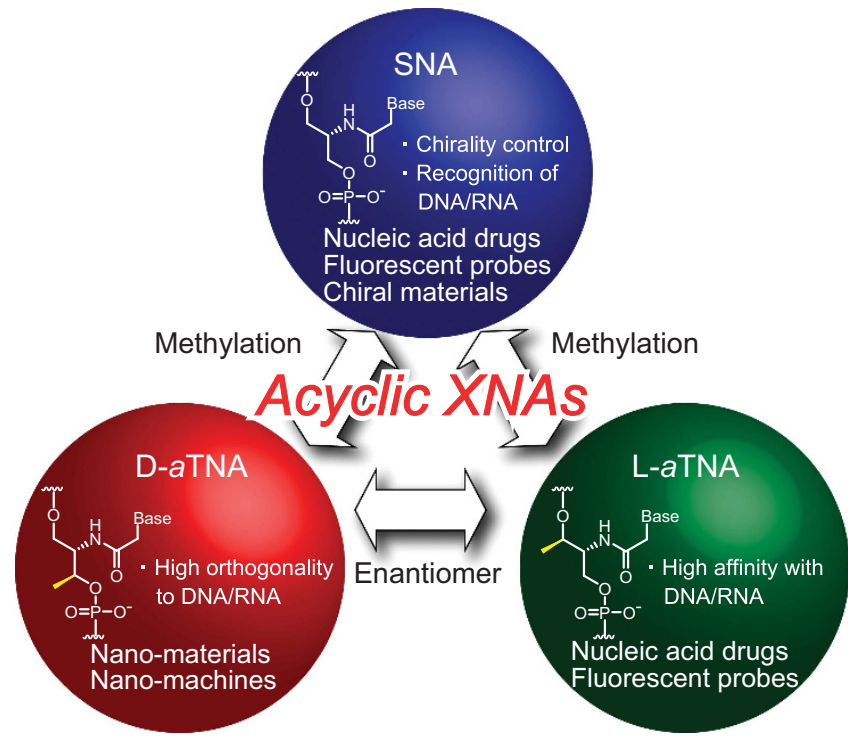

Figure 7 Characteristics and possible applications of acyclic XNAs described in this paper.

differences are small. This suggests that additional acyclic XNAs with novel functions can be developed by tuning the chemical structure of the monomer.

\section{CONFLICT OF INTEREST}

The authors declare no conflict of interest.

\section{ACKNOWLEDGEMENTS}

This work was supported by PRESTO, Japan Science and Technology Agency to HK and by the Ministry of Education, Culture, Sports, Science and Technology, Japan through a Grant-in-Aid for Scientific Research (25248037) and on Innovative Areas 'Molecular Robotics' (24104005).

1 Leumann, C. J. DNA analogues: from supramolecular principles to biological properties. Bioorg. Med. Chem. 10, 841-854 (2002).

2 Pinheiro, V. B. \& Holliger, P. Towards XNA nanotechnology: new materials from synthetic genetic polymers. Trends Biotechnol. 32, 321-328 (2014).

3 Zhang, S., Switzer, C. \& Chaput, J. C. The resurgence of acyclic nucleic acids. Chem. Biodiversity 7, 245-258 (2010).

4 Nielsen, P. E., Egholm, M., Berg, R. H. \& Buchardt, O. Sequence-selective recognition of DNA by strand displacement with a thymine-substituted polyamide. Science 254 , 1497-1500 (1991).

5 Sacui, I., Hsieh, W.-C., Manna, A., Sahu, B. \& Ly, D. H. Gamma peptide nucleic acids: as orthogonal nucleic acid recognition codes for organizing molecular self-assembly. J. Am. Chem. Soc. 137, 8603-8610 (2015).

6 Sforza, S., Haaima, G., Marchelli, R. \& Nielsen, P. E. Chiral peptide nucleic acids (PNAs): helix handedness and DNA recognition. Eur. J. Org. Chem. 1999, 197-204 (1999)

7 Sforza, S., Tedeschi, T., Corradini, R. \& Marchelli, R. Induction of helical handedness and DNA binding properties of peptide nucleic acids (PNAs) with two stereogenic centres. Eur. J. Org. Chem 2007, 5879-5885 (2007).

8 Stirchak, E. P., Summerton, J. E. \& Weller, D. D. Uncharged stereoregular nucleic acid analogs: 2. Morpholino nucleoade otigomers with carbamate internucleoside linkages. Nucleic Acids Res. 17, 6129-6141 (1989).

9 Obika, S., Nanbu, D., Hari, Y., Morio, K.-i., In, Y., Ishida, T. \& Imanishi, T. Synthesis of 2'-O,4'-C-methyleneuridine and -cytidine. Novel bicyclic nucleosides having a fixed C3, -endo sugar puckering. Tetrahedron Lett. 38, 8735-8738 (1997).

10 Koshkin, A. A., Singh, S. K., Nielsen, P., Rajwanshi, V. K., Kumar, R., Meldgaard, M., Olsen, C. E. \& Wengel, J. LNA (locked nucleic acids): synthesis of the adenine, cytosine, guanine, 5-methylcytosine, thymine and uracil bicyclonucleoside monomers, oligomerisation, and unprecedented nucleic acid recognition. Tetrahedron 54, 3607-3630 (1998).

11 Renneberg, D. \& Leumann, C. J. Watson - Crick base-pairing properties of tricyclo-DNA. J. Am. Chem. Soc. 124, 5993-6002 (2002).
12 Kaur, H., Babu, B. R. \& Maiti, S. Perspectives on chemistry and therapeutic applications of locked nucleic acid (LNA). Chem. Rev. 107, 4672-4697 (2007).

13 Peng, L. \& Roth, H.-J. Synthesis and properties of $2^{\prime}$-deoxy- $1^{\prime}, 2^{\prime}$-seco-D-ribosyl $\left(5^{\prime} \rightarrow 3^{\prime}\right)$ oligonucleotides $\left(=1^{\prime}, 2^{\prime}\right.$-seco-DNA $)$ containing adenine and thymine. Helv. Chim. Acta 80, 1494-1512 (1997).

14 Ramasamy, K. S. \& Seifert, W. Amino acid nucleic acids: synthesis and hybridization properties of a novel class of antisense oligonucleotides. Bioorg. Med. Chem. Lett. 6 , 1799-1804 (1996).

15 Benhida, R., Devys, M., Fourrey, J.-L., Lecubin, F. \& Sun, J.-S. Incorporation of serino derived acyclic nucleoside analogues into oligonucleotides: influence on duplex and triplex formation. Tetrahedron Lett. 39, 6167-6170 (1998).

16 Rana, V. S., Kumar, V. A. \& Ganesh, K. N. Oligonucleotides with (N-thymin-1-ylacetyl) 1-phenylserinol in backbone: chiral acyclic analogues that form dna triplexes. Bioorg. Med. Chem. Lett. 7, 2837-2842 (1997).

17 Vandendriessche, F., Augustyns, K., Van Aerschot, A., Busson, R., Hoogmartens, J. \& Herdewijn, P. Acyclic oligonucleotides: possibilities and limitations. Tetrahedron 49, 7223-7238 (1993).

18 Schneider, K. C. \& Benner, S. A. Oligonucleotides containing flexible nucleoside analogs. J. Am. Chem. Soc. 112, 453-455 (1990).

19 Merle, Y., Bonneil, E., Merle, L., Sági, J. \& Szemzö, A. Acyclic oligonucleotide analogues. Int. J. Biol. Macromol. 17, 239-246 (1995).

20 Heuberger, B. D. \& Switzer, C. A pre-RNA candidate revisited: both enantiomers of flexible nucleoside triphosphates are DNA polymerase substrates. J. Am. Chem. Soc. 130, 412-413 (2007).

21 Nielsen, P., Dreiøe, L. H. \& Wengel, J. Synthesis and evaluation of oligodeoxynucleotides containing acyclic nucleosides: introduction of three novel analogues and a summary. Bioorg. Med. Chem. 3, 19-28 (1995).

22 Langkjær, N., Pasternak, A. \& Wengel, J. UNA (unlocked nucleic acid): a flexible RNA mimic that allows engineering of nucleic acid duplex stability. Bioorg. Med. Chem. 17, 5420-5425 (2009).

23 Zhang, L., Peritz, A. \& Meggers, E. A simple glycol nucleic acid. J. Am. Chem. Soc. 127, 4174-4175 (2005).

24 Schlegel, M. K., Essen, L.-O. \& Meggers, E. Atomic resolution duplex structure of the simplified nucleic acid GNA. Chem. Commun. 46, 1094-1096 (2010).

25 Schlegel, M. K., Xie, X., Zhang, L. \& Meggers, E. Insight into the high duplex stability of the simplified nucleic acid GNA. Angew. Chem. Int. Ed. 48, 960-963 (2009).

26 Schlegel, M. K., Peritz, A. E., Kittigowittana, K., Zhang, L. \& Meggers, E. Duplex formation of the simplified nucleic acid GNA. ChemBioChem 8, 927-932 (2007).

27 Karri, P., Punna, V., Kim, K. \& Krishnamurthy, R. Base-pairing properties of a structural isomer of glycerol nucleic acid. Angew. Chem. Int. Ed. 52, 5840-5844 (2013).

28 Kumar, V., Gore, K. R., Pradeepkumar, P. I. \& Kesavan, V. Design, synthesis, biophysical and primer extension studies of novel acyclic butyl nucleic acid (BuNA). Org. Biomol. Chem. 11, 5853-5865 (2013).

29 Li, P., Sun, J., Su, M., Yang, X. \& Tang, X. Design, synthesis and properties of artificial nucleic acids from (R)-4-amino-butane-1,3-diol. Org. Biomol. Chem. 12, 2263-2272 (2014).

30 Eschenmoser, A. Etiology of potentially primordial biomolecular structures: from vitamin B12 to the nucleic acids and an inquiry into the chemistry of life's origin - a retrospective. Angew. Chem. Int. Ed. 50, 12412-12472 (2011).

31 Robertson, M. P. \& Joyce, G. F. The origins of the RNA world. Cold Spring Harb. Perspect. Biol. 4, a003608 (2012).

32 Kashida, H., Liang, X. G. \& Asanuma, H. Rational design of functional DNA with a non-ribose acyclic scaffold. Curr. Org. Chem 13, 1065-1084 (2009).

33 Asanuma, H., Kashida, H. \& Kamiya, Y. De novo design of functional oligonucleotides with acyclic scaffolds. Chem. Rec. 14, 1055-1069 (2014).

34 Asanuma, H., Toda, T., Murayama, K., Liang, X. \& Kashida, H. Unexpectedly stable artificial duplex from flexible acyclic threoninol. J. Am. Chem. Soc. 132, 14702-14703 (2010).

35 Murayama, K., Tanaka, Y., Toda, T., Kashida, H. \& Asanuma, H. Highly stable duplex formation by artificial nucleic acids acyclic threoninol nucleic acid (aTNA) and serinol nucleic acid (SNA) with acyclic scaffolds. Chem. Eur. J. 19, 14151-14158 (2013).

36 Kashida, H., Murayama, K., Toda, T. \& Asanuma, H. Control of the chirality and helicity of oligomers of serinol nucleic acid (SNA) by sequence design. Angew. Chem. Int. Ed. 50, 1285-1288 (2011).

37 Murayama, K., Kashida, H. \& Asanuma, H. Acyclic I-threoninol nucleic acid (I-aTNA) with suitable structural rigidity cross-pairs with DNA and RNA. Chem. Commun. 51, 6500-6503 (2015).

38 Dragulescu-Andrasi, A., Rapireddy, S., Frezza, B. M., Gayathri, C., Gil, R. R. \& Ly, D. H. A simple $\gamma$-backbone modification preorganizes peptide nucleic acid into a helical structure. J. Am. Chem. Soc. 128, 10258-10267 (2006).

39 Tedeschi, T., Sforza, S., Dossena, A., Corradini, R. \& Marchelli, R. Lysine-based peptide nucleic acids (PNAs) with strong chiral constraint: control of helix handedness and DNA binding by chirality. Chirality 17, S196-S204 (2005).

40 Murayama, K., Kamiya, Y., Kashida, H. \& Asanuma, H. Ultrasensitive molecular beacon designed with totally serinol nucleic acid (SNA) for monitoring mRNA in cells. ChemBioChem 16, 1298-1301 (2015).

41 Kamiya, Y., Takai, J., Ito, H., Murayama, K., Kashida, H. \& Asanuma, H. Enhancement of stability and activity of siRNA by terminal substitution with serinol nucleic acid (SNA). ChemBioChem 15, 2549-2555 (2014). 

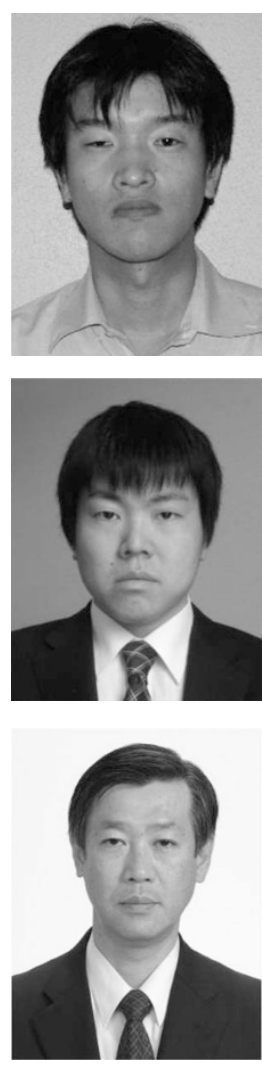

Dr Hiromu Kashida was born in Niigata Prefecture, Japan in 1979. He received his PhD in 2006 from The University of Tokyo under the supervision of Prof. Makoto Komiyama. He became an Assistant Professor at Nagoya University in 2007 and was promoted as Associate Professor in 2011. He is currently an Associate Professor at the Graduate School of Engineering, Nagoya University. He has received the PCCP Prize from the Royal Society of Chemistry (2011), the Chemical Society of Japan Award for Young Chemists (2014) and the Award for Encouragement of Research in Polymer Science, The Society of Polymer Science, Japan (2015). His research interests include the design of functional artificial nucleic acids and the photochemistry using DNA scaffolds.

Dr Keiji Murayama was born in Mie Prefecture, Japan, in 1987. He received his PhD in 2015 from the Nagoya University under the supervision of Prof. Hiroyuki Asanuma. After working as postdoctoral fellow of Venture Business Laboratory (VBL) in Nagoya University, he is currently an Assistant Professor at the Graduate School of Engineering, Nagoya University. His research interests are in the area of the artificial nucleic acids.

Dr Hiroyuki Asanuma was born in Nagano Prefecture, Japan in 1962. He received his $\mathrm{PhD}$ in 1989 from The University of Tokyo. He joined Fuji Photo Film Co. Ltd. as a researcher, and then moved to The University of Tokyo in 1995 as an Assistant Professor. He was promoted as Associate Professor in 2000 and moved to the Graduate School of Engineering, Nagoya University as a full professor in 2005. Currently his research interests are focused on the development of functional artificial oligonucleotides with acyclic scaffolds, such as (1) photoregulation of DNA and RNA functions, (2) design of new XNAs, (3) new fluorescent probes for practical applications, (4) design of nucleic acid-based drugs, and (5) assembled functional molecules. 